\title{
Exploration of Talents Training Mode of Mathematics and Applied Mathematics in Local Colleges and Universities under the Visualization of Transformation and Development
}

\author{
Kangbo Liu \\ Jiangxi vocational college of Industry \& Engineering, Pingxiang, Jiangxi 337000, China
}

Keywords: transformation and development; local colleges and universities; mathematics and applied mathematics; talent training model

Abstract: Talent cultivation is the main goal of local college education. Especially under the current severe employment situation, the quality of employment has a very important relationship with the students' actual professional ability, which is especially true for mathematics and applied mathematics. Under the vision of transformation and development, the requirements for talents are getting higher and higher, especially the cultivation of students' application abilities. However, there are still some problems in the talent training in traditional local colleges and universities in mathematics and applied mathematics teaching, this paper conducts in-depth analysis of the characteristics of mathematics and applied mathematics teaching in local colleges and universities, based on a more detailed description of the effective model of personnel training.

\section{Introduction}

In the current situation of college education, with the continuous increase in the number of enrolled students, the employment situation has become extremely severe. Therefore, in order to make students stand out from the fierce competition, local colleges and universities should actively establish a good model of personnel training. Especially in the vision of transformation and development, the demand for the quality of personnel training has become higher and higher. Under such circumstances, local colleges and universities should actively explore and establish effective ways for personnel training, especially in mathematics and applied mathematics. However, due to the influence of traditional education concepts, local colleges and universities still have some problems in the teaching process of mathematics and applied mathematics. If these issues are not solved in a timely and effective manner, they will become the main obstacle for local colleges and universities to adapt to the transformation and development situation. 


\section{Main Problems in Talent Cultivation in Mathematics and Applied Mathematics in Local Colleges and Universities}

\subsection{Lack of scientific and reasonable planning for teaching content}

For students, in the process of learning, whether the teaching content of the teacher is scientific and reasonable is very critical, which directly relates to the degree of acceptance and understanding of the students. The same knowledge content, if the teacher before the lecture, the scientific and rational planning of teaching content, and in the teaching process in strict accordance with the established plan to carry out teaching activities, students will accept and understand knowledge quickly, but on the contrary, students The study will be affected by certain [1]. In the teaching practice of current local universities in mathematics and applied mathematics, the phenomenon of unscientific teaching content is ubiquitous. Some teachers are eager to instill theoretical knowledge and formulate teaching plans in order to pursue the overall quality of teaching and teaching effects. It is entirely in accordance with its own wishes. Simply thinking that improving teaching standards can improve the overall quality of students. Therefore, students' learning and growth characteristics are neglected in the teaching practice, which leads to inconsistency between students' learning and actual intellectual development. The expected role of improving the quality of teaching may, on the contrary, have a greater adverse impact on students' later learning and it is difficult to adapt to the actual requirements of transformation and development.

\subsection{The excessively formal application of teaching methods and lack of substantive significance}

The new round of curriculum reform has been going on for some time and has achieved some initial results. With the progress of curriculum reform, some of the more innovative teaching methods have gradually emerged. Many of these teaching methods are very effective. The application of mathematics and applied mathematics in local colleges and universities has changed the traditional teaching methods and teaching concepts and greatly improved the overall quality of teaching [2]. However, there are still some problems in this process. Due to the influence of some teachers' inherent teaching concepts, the acceptability of these new teaching methods is relatively low, and there is also a certain bias in their understanding. Therefore, in the process of practical application, these teachers are also influenced by the trend of curriculum reform and pursue the innovation of teaching forms. Only the formal application, some teachers even over-pursed the teaching form and neglected the original purpose of teaching. On the surface, the teacher applied the new teaching method better, but in fact it did not play the expected role of the teaching method. Sometimes, even because of the pursuit of teaching forms, it takes a lot of class time, which affects the overall quality of teaching, and it also greatly restricts the overall quality of talent.

\subsection{Lack of summarily and feedback of mathematical knowledge}

According to the normal learning rules, after learning new knowledge points, students need to make corresponding summary and feedback in a timely manner, so as to better help students understand and master new knowledge, and then have the ability to be practically applied, and become a vision of transformation and development. Excellent talent [3]. The new curriculum standards also regard students' practical application ability as the main training objective. However, from the current situation of teaching mathematics and applied mathematics in local colleges and universities, there is no process of training and feedback for new knowledge in the teaching process. The pursuit of teaching progress often ignores the process of knowledge training and application. 
After the students learn new knowledge, the teacher should carry out targeted training in a timely manner and examine the students' mastery of knowledge from different perspectives. In the course of practice, the teacher can timely It is found that students still have poor knowledge of what to master, which areas are prone to problems, and then carry out targeted explanations to promote students' better understanding and mastery. However, unfortunately, in the teaching of mathematics and applied mathematics in local colleges and universities The general lack of training and feedback process, the students' mastery of new knowledge is uneven, affecting the overall quality of personnel training.

\section{The Transformation of Personnel Training of Mathematics and Applied Mathematics in Local College and Universities Should Pay Attention to Basic Issues}

\subsection{Paying attention to the systematic of knowledge in mathematics and applied mathematics and consolidate students' mathematical foundations}

In the teaching practice, knowledge is highly systematic. Therefore, in the vision of transformation and development, the mathematics and applied mathematics majors of local colleges and universities should also follow the systematic nature of mathematics knowledge in the process of personnel training so as not to separate the integrity of knowledge. Causes understanding obstacles. In the current era of network development, fragmented information knowledge is flooding the entire network. Affected by this, some current teachers also implement fragmented teaching in the process of training mathematics and applied mathematics professionals in local colleges and universities, without paying attention to the continuity of knowledge. Students in the process of learning are also one-sided, lack of systematic understanding, in the actual use of the process can not think of the relevant knowledge in time, resulting in a greater adverse effect on the learning effect [4]. Therefore, in order to effectively improve the overall quality of the training of mathematics and applied mathematics professionals in local colleges and universities in the transformation and development, and to give play to the practical role of teaching, we should pay attention to the systematic nature of mathematics knowledge, and make reasonable plans in the process of talent cultivation to help students establish Complete knowledge system, clear knowledge of the ins and outs of the knowledge, take the course education goal as the main line, identify key connection points, deepen talent training into all aspects of mathematics and applied mathematics teaching, grasp the systematic and integrity of knowledge, and effectively Improve the quality of personnel training.

\subsection{Students should be the main body in the process of personnel training}

In the learning process, students are not passive recipients of knowledge, but based on their own knowledge system, they constantly enrich and improve new knowledge and build a knowledge framework to improve their overall quality. These are all students should take the initiative to complete. However, under the traditional concept of education, the students' initiative has not been maximized. The main position in the classroom has been completely replaced by the teacher's explanation. The students learn in full accordance with the teacher's ideas and lack active thinking. 5]. Therefore, when teaching mathematics and applied mathematics, teachers should pay full attention to the student's dominant position, actively innovate the form of talent training, give full play to the guiding role of teachers, improve the subjective initiative of students, and guide students to actively and actively think and change passive acceptance. The teaching malpractice of knowledge has enabled students to gradually develop independent learning habits and enhance their confidence in 
learning. This lays a solid foundation for the transformation and development of visual quality training for local mathematics and applied mathematics professionals in local universities.

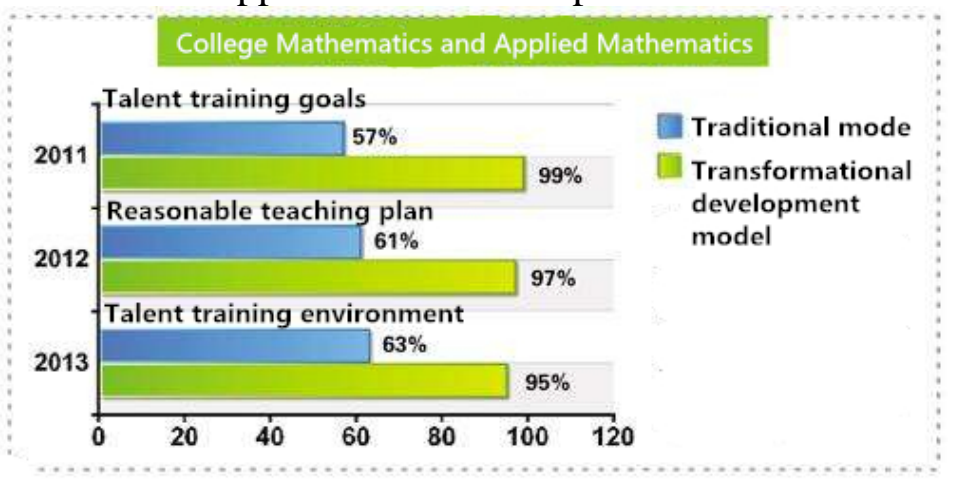

Fig. 1 Comparison of the effects of talents cultivation in mathematics and applied mathematics in colleges and universities

4. The Effective Mode for the Development of Talents in Mathematics and Applied Mathematics in Local Colleges and Universities

\subsection{Establish clear talent training objectives}

In the current process of the teaching of mathematics and applied mathematics in local universities, the unclear teaching objectives are one of the major problems affecting the quality of personnel training. In order to fundamentally solve this problem, teachers should first establish clear talents before teaching. Training objectives [6]. Specifically, teachers should be guided by the teaching syllabus of mathematics and applied mathematics in local colleges and universities. Under the premise of meeting mathematics teaching standards, they should have a deep understanding of students' mathematics learning and mastery of knowledge, and then combine the curriculum standards and formulate scientific and rational Teaching goals. Abandoning the wrong teaching methods that used to randomly arrange classes according to one's will, through the scientific teaching design, help students build a complete knowledge system of mathematics. While explaining the points of new knowledge, taking into account the knowledge learned and gradually improving the overall quality of students, to promote the quality of talents in mathematics and applied mathematics in local colleges and universities to continuously improve.

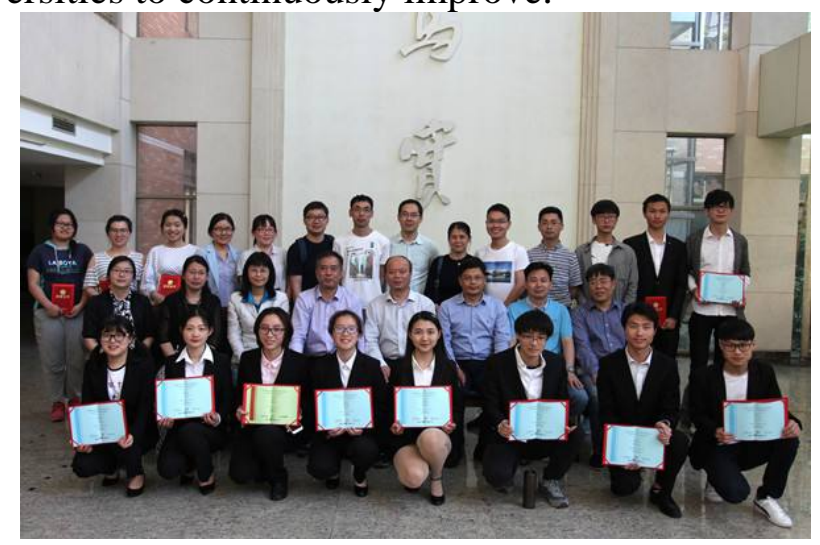

Fig. 2 Establishing a clear talent training goal 


\subsection{Develop a scientific and reasonable teaching plan and regard the training of personnel as the main goal of teaching}

The scientific and rational teaching plan is a key factor to guarantee the quality of teaching, and it is also an effective form of talent training for local colleges in mathematics and applied mathematics under the vision of transformation and development. Therefore, in the teaching practice of mathematics and applied mathematics in local colleges and universities, in order to effectively improve the overall talent cultivation Quality, should first of all develop a scientific and rational teaching plan, the training of personnel as the main goal of teaching [7]. In this process, teachers should combine the characteristics of students' learning with the characteristics of students' growth and mental development. This is the most easily overlooked problem in the process of formulating learning plans. Because of the influence of traditional education concepts, teachers have paid too much attention to teaching progress during the teaching process, so blindly inculcating knowledge has a greater adverse effect on the teaching plan. Teachers should take into account the personality and common characteristics of the students in the process of formulating teaching plans, clarify reasonable teaching objectives, highlight students' learning abilities, and optimize the structure of classroom teaching according to the teaching plan, and reasonably arrange class schedules to solve problems in time. Problems, to ensure that students can fully learn and understand the new knowledge, experience the sense of achievement in learning, and effectively improve the quality of the training of local college mathematics and applied mathematics professionals in the transformation and development.

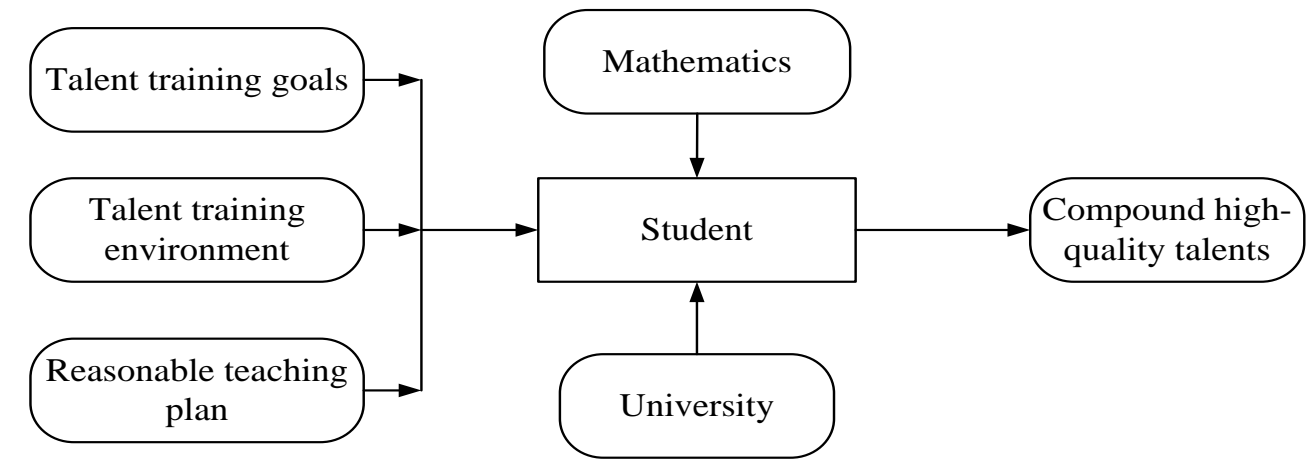

Fig. 3 Transforming and Developing Visual Talent Training Model under Mathematics

\subsection{Create a good environment for talent cultivation and promote better learning and promotion of students}

The learning environment has a very important influence on students' learning. Therefore, in the teaching process, the teacher should pay attention to the creation of the teaching environment. Classroom is the main place for students to learn. Teachers should make more efforts to create a good classroom environment and actively adopt various effective methods to create a teaching environment that is most suitable for students to learn and promote students to better understand and master the teaching environment. Knowledge [8]. With the optimization and upgrading of teaching methods, a variety of new teaching forms have emerged. These teaching forms have a very obvious effect on creating a good classroom teaching environment and improving the overall quality of teaching. Under the vision of transformation and development, teachers in the field of mathematics and applied mathematics training in local colleges and universities can use multimedia technology as their main carrier. This will not only change the boring nature of traditional teaching forms, inspire students' interest in learning, but also be active to a certain extent. Classroom teaching atmosphere 
creates a good teaching environment, and then plays a role in improving teaching quality.

\section{Conclusion}

In summary, under the vision of transformation and development, the mathematics and applied mathematics majors of local colleges and universities should actively change the traditional teaching methods, regard the cultivation of talents as the main goal of teaching, constantly innovate and improve the form of personnel training, and improve the overall quality of personnel training, and promote Students grow and develop better.

\section{References}

[1] Xiong Mei, Zhang Dalin, Yan Zhongquan, et al. Exploration of the mode of training of talents for mathematics and applied mathematics in local colleges under the vision of transformation and development. Journal of Qiannan Normal University for Nationalities, Vol. 6, (2015), p.52-55.

[2] Xiao Chunmei, Lang Yaoxiu, Mo Miao, et al. Exploration of Talents Training Mode of Coherent Basic Education Mathematics Teachers in Local Colleges in the Background of Transformation Development. Journal of Inner Mongolia Normal University (Education Science Edition), Vol. 9, (2017), p.80-84.

[3] Ma Xiaoyan, Guo Zhongjin, Sun Li, et al. Research and practice of classified training model for applied talents in local universities--Taking the specialty of mathematics and applied mathematics in Taishan University as an example. Journal of Qilu Normal University, Vol. 6, (2015), p.12-15.

[4] Li Yong, et al. Exploration and Preliminary Practice in the Reform of Education and Teaching System of Mathematics and Applied Mathematics in the Background of Transformation and Development. Higher Education Forum, Vol. 1, (2017), p.23-27.

[5] Fang Jiating, et al. The establishment and research of mathematics experiment course system under the background of transitional development. Curriculum, Vol. 33, (2015), p.141.

[6] Li Bingjun, et al. Reform and exploration of training mode for mathematics majors in local universities. Industry and Technology Forum, Vol. 20, (2015), p.180-180.

[7] Chen Xiusu, Chen Rui, Ding Xuanhao, et al. Exploration and practice of the training mode for the talents of mathematics and applied mathematics which highlights the characteristics of finance. Journal of Chongqing Technology and Business University (Natural Science Edition), Vol. 5, (2017), p.26- 30.

[8] Jiang Xiaoyun, Xie Haibin, Li Zhilan, et al. Development of talent training program for mathematics and applied mathematics in normal colleges and universities. Journal of Guilin Teachers College, Vol. 6, (2017), p.108-112. 